\title{
The role of stressors in altering eco-evolutionary dynamics
}

\author{
Loukas Theodosiou ${ }^{1,2}$ (D) \\ Teppo Hiltunen ${ }^{3,4}$ \\ Lutz Becks ${ }^{1,5}$ (D)
}

${ }^{1}$ Community Dynamics Group, Max Planck Institute for Evolutionary Biology, Plön,

Germany

${ }^{2}$ Department of Microbial Population

Biology, Max Planck Institute for

Evolutionary Biology, Plön, Germany

${ }^{3}$ Department of Microbiology, University of Helsinki, Helsinki, Finland

${ }^{4}$ Department of Biology, University of Turku, Turku, Finland

${ }^{5}$ Limnology - Aquatic Ecology and Evolution, Limnological Institute, University of Konstanz, Konstanz, Germany

\section{Correspondence}

Loukas Theodosiou

Email: theodosiou@evolbio.mpg.de

\section{Funding information}

German Research Foundation, Grant/Award Number: 9; Finnish Academy, Grant/Award Number: 294666; Helsinki Institute of Life Science (HiLIFE)

\begin{abstract}
1. We review and synthesize evidence from the fields of ecology, evolutionary biology and population genetics to investigate how the presence of abiotic stress can affect the feedback between ecological and evolutionary dynamics.

2. To obtain a better insight of how, and under what conditions, an abiotic stressor can influence eco-evolutionary dynamics, we use a conceptual predator-prey model where the prey can rapidly evolve antipredator defences and stress resistance.

3. We show how abiotic stress influences eco-evolutionary dynamics by changing the pace and in some case the potential for evolutionary change and thus the evolution-to-ecology link. Whether and how the abiotic stress influences this link depends on the effect on population sizes, mutation rates, the presence of gene flow and the genetic architecture underlying the traits involved.

4. Overall, we report ecological and population genetic mechanisms that have so far not been considered in studies on eco-evolutionary dynamics and suggest future research directions and experiments to develop an understanding of the role of eco-evolutionary dynamics in more complex ecological and evolutionary scenarios.

\section{KEYWORDS}

eco-evolutionary dynamics, genetic architecture, genetic variation, migration, predator-prey interaction, trade-off
\end{abstract}

\section{INTRODUCTION}

When adaptive evolution of ecologically important traits is rapid, for example, occurring within just a few generations (e.g., Grant \& Grant, 2002), evolutionary change can have an impact on ecological change in the same species or in interacting species (Charlesworth, 1971; Pimentel, 1968). For example, rapid evolution of prey defence or resistance has altered the ecological dynamics in several experimental plankton studies (Frickel, Feulner, Karakoc, \& Becks, 2018; Frickel, Sieber, \& Becks, 2016; Yoshida, Jones, Ellner, Fussmann, \& Hairston, 2003). Guppies (Poecilia reticulata) rapidly evolve different life-history strategies under different levels of predation, further affecting interactions with their predators (Post \& Palkovacs, 2009; Reznick, 1982) and whole-ecosystem processes (Bassar et al., 2010). When curly-tailed lizards (Leiocephalus carinatus) were introduced into the Bahamas, their prey (the brown anoles, Anolis sagrei) fled into the trees. This response contributed to rapid selection for longer limbs in the brown lizards and to an increase in their population size (Steinberg et al., 2014). These and other studies underline the importance of using an eco-evolutionary perspective for understanding the dynamics of populations and species interactions (Andrade-Domínguez, Salazar, Del Carmen Vargas-Lagunas, Kolter, \& Encarnación, 2014; Brunner, Anaya-Rojas, Matthews, \& Eizaguirre, 2017; Grant \& Grant, 2002; Matthews, Aebischer, Sullam, Lundsgaard-Hansen, \& Seehausen, 2016).

Abiotic stress can affect eco-evolutionary dynamics in a variety of ways, by altering the strength of selection, the response to selection for ecologically relevant traits and/or by directly altering the population dynamics, which in turn feeds back onto trait evolution. An increased understanding of the effects of abiotic stress 
on eco-evolutionary dynamics will be important for our ability to preserve species, communities and ecosystem functions. However, to the best of our knowledge, there are only very few studies to date that have directly focused on these effects (see Alberti, 2015; Hendry, 2017, Hiltunen et al., 2018). In the following, we will use thought experiments and conceptual models, complementing them with relevant data whenever possible to highlight potential ecological and genetic conditions that favour or disfavour, or change the qualitative outcome of eco-evolutionary dynamics (see contributions to the special issue by Hendry and De Meester). We focus on abiotic stressors, defined as abiotic factors that lead to a sharp reduction in population mean fitness (Alberto et al., 2013; Macnair, 1997).

We aim to develop general predictions for the link between evolutionary and ecological change in the presence and absence of an abiotic stressor. We focus on predator-prey interactions as an example, as these are commonplace in nature and have provided many examples of eco-evolutionary dynamics involving, for example, theoretical models (Abrams \& Matsuda, 1997; DeLong et al., 2016; DeLong \& Gibert, 2016; Huang, Traulsen, Werner, Hiltunen, \& Becks, 2017; Jones \& Ellner, 2007), bacterium-protozoon systems (Hiltunen \& Becks, 2014; Hiltunen, Kaitala, Laakso, \& Becks, 2017), alga-rotifer systems (Hairston, Ellner, Geber, Yoshida, \& Fox, 2005; Jones, Ferrière, \& Bronstein, 2009; Yoshida et al., 2003), fish-fish predation (Bassar et al., 2010; Reznick, 1982; Travis et al., 2014) or fish-zooplankton interactions (Post \& Palkovacs, 2009; Walsh \& Post, 2011). We consider different scenarios, where the prey population can evolve antipredatory defence with or without costs (trade-offs), as well as resistance to the abiotic stressor. For the sake of simplicity, we assume that the predator does not evolve a counter-adaptation to the prey's defence or in response the abiotic stressor. Specifically, we will provide examples of how abiotic stress can alter antipredator defence evolution for the prey (i.e., the pace of evolution and fitness effects) and thus impact on the ecological dynamics of predator and prey. Furthermore, we compare eco-evolutionary dynamics in the absence versus the presence of the abiotic stressor. We explore the consequences of the stressor on standing genetic variation in the prey, and how the effect of stress on eco-evolutionary dynamics depends on fitness trade-offs, mutation rates and gene flow. Beyond the hypothetical predator-prey system, the concepts we develop have broader applications for other types of species interactions, for example, host-parasite interactions, competition or mutualism.

\subsection{Eco-evolutionary dynamics in a predator- prey system}

In a classical predator-prey system without evolution (upper panels in Figure 1), models suggest three qualitatively different outcomes: extinctions, steady-state dynamics or cycles with a characteristic quarter-phase lag between the changes in prey and predator population sizes (Barbosa \& Castellanos, 2005; Hörnfeldt, 1978; Krebs et al., 1995; Utida, 1957; Velzen \& Gaedke, 2017). All three possibilities have been observed in field and experimental data (e.g., Jones \& Ellner, 2007; Yoshida et al., 2003).

The population dynamics of predator and prey might be altered if adaptive prey evolution reduces predator consumption. The prey might be rescued from extinction and be able to coexist with the predator (Gomulkiewicz \& Holt, 1995; Jones, 2008), either in a stable equilibrium or via cyclic dynamics (Figure 1, scenario (a)). With predator and prey already in a steady state, prey evolution might lead to an increase in the prey and a decrease in the predator population size (Figure 1, scenario (b)). Alternatively, when the defence incurs a cost of reduced prey population growth, prey densities might remain similar, but the predator population would still decline, or predator-prey
Scenario a

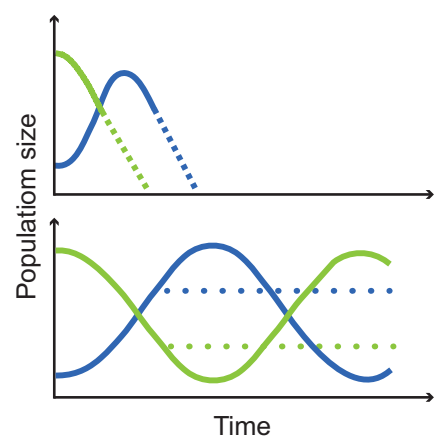

Scenario b

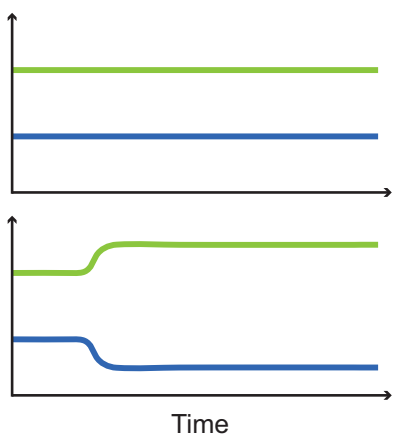

Scenario c
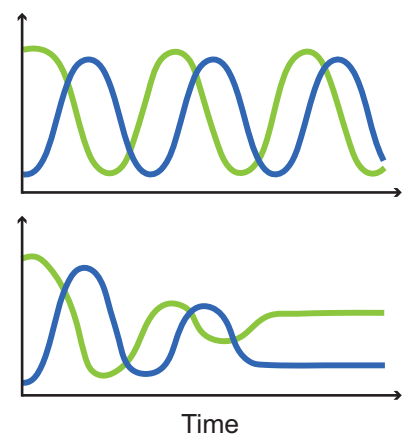

- Prey
Scenario d

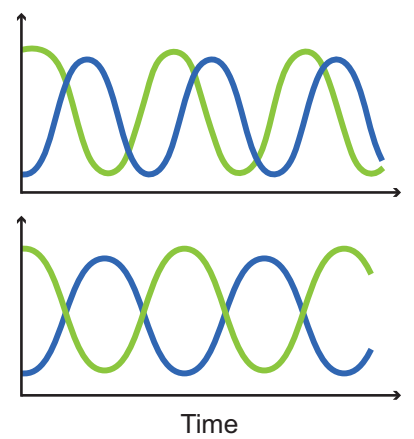

- Predator

FIGURE 1 Ecological dynamics (top) and eco-evolutionary dynamics (bottom) in a hypothetical predator-prey system (prey = green, predator = blue). Scenario (a) describes an evolutionary rescue scenario where the prey will become extinct (followed by the predator), without the evolution of an antipredator defence trait in the prey population (arrow). In scenario (b), the prey defence evolution leads to higher prey population but lower predator population sizes. In scenario (c), prey evolution without maintained polymorphism leads to dampening the amplitude of quarter-phase cycles. For scenario (d), we assume that the prey defence arises at the cost of reduced competitiveness and the prey population maintains a polymorphism of defended and undefended individuals. This polymorphism can lead to eco-evolutionary feedback dynamics 
cycles might be stabilized through prey evolution where the defended prey replaces the undefended over time (Figure 1, scenario (c), Becks, Ellner, Jones, \& Hairston, 2010; Ehrlich, Becks, \& Gaedke, 2017; Jones \& Ellner, 2004, 2007, Yoshida et al., 2003).

A trade-off between defence and growth is also important in the fourth case, where predator-prey cycles change from a quarterphase lag to antiphase cycles; that is, predator densities are highest when prey densities are lowest and vice versa (Figure 1, scenario (d)) (Abrams \& Matsuda, 1997; Jones \& Ellner, 2004, 2007; Yoshida et al., 2003). Antiphase cycles occur when the defence is very costly but effective against consumption by the predator, allowing the maintenance of a polymorphism within the prey population (Becks et al., 2010; Kasada, Yamamichi, \& Yoshida, 2014). Low predator densities select for the competitive and less defended prey type, whereas high predator densities lead to selection for the defended but less competitive prey type (ecology-to-evolution link). Conversely, predator density decreases when defended prey is abundant and increases when undefended prey is at high densities (evolution-to-ecology link). These ecological and evolutionary changes can occur continuously over long timescales, creating an ongoing link from ecology to evolution and back, called an eco-evolutionary feedback loop (as defined in Post \& Palkovacs, 2009). These feedback dynamics are different from the other scenarios described above, as there is a continuous feedback between the evolutionary and ecological change. In contrast, the interaction between the evolutionary and ecological dynamics is short or transient for stabilizing dynamics or evolutionary rescue. Besides evolutionary rescue, antiphase cycles are the only type of eco-evolutionary dynamics that has been repeatedly demonstrated to date (Becks et al., 2010; Hiltunen \& Becks, 2014; Turchin, 2003a, 2003b; Velzen \& Gaedke, 2017; Yamamichi \& Ellner, 2016; Yoshida et al., 2003). Understanding the patterns of population dynamics is thus one of the most promising ways to study the factors affecting the evolution-to-ecology link. In the following, we will discuss cases where this link between evolutionary change in the prey and predator-prey dynamics is broken (i.e., evolutionary change comes to a halt) or altered (i.e., the pace of evolution evolutionary change is altered and thus its effect ecological changes) due to the addition of an abiotic stressor leading to quantitatively or qualitatively different eco-evolutionary dynamics.

\subsection{Reduction in standing genetic variation}

Changes in the standing genetic variation (i.e., changes in the presence of alternative forms of a gene at a given locus in a population (Barrett \& Schluter, 2008)) can influence population dynamics when frequency change in phenotypic traits affect demographic rates. Experimental and theoretical evidence has shown that the amount of genetic variation can affect the link of rapid evolution to population dynamics (Becks et al., 2010; Cortez, 2017; Steiner \& Masse, 2013), with increasing additive genetic variation leading to a higher probability of altering the population dynamics. Thus, factors or processes that affect standing genetic variation can have a substantial impact on the evolution-to-ecology link.
The introduction of an abiotic stressor to the predator-prey system (Figure 1) can severely decrease the effective population size of the prey. The average amount of standing genetic variation in the prey population is expected to decline with a rate that depends on the effective population size (Hill, 1972; Kimura, 1983; Wright, 1931, 1968). Also, a reduction in effective population size will also decrease the influx of new mutations in the populations (Raynes \& Sniegowski, 2014). Thus, we would expect the prey population to respond less efficiently to selection for antipredator defence after the introduction of an abiotic stressor with consequences for the link from evolution to ecology (Figure 1). With the reduction in genetic variation, defence evolution will be slow and, depending on circumstances, evolutionary rescue may fail (Scenario (a) in Figure 1); both populations may remain at low densities (Scenario (b) in Figure 1), at steady state (Scenario (c) in Figure 1); or antiphase cycles might be replaced by classic quarter-phase shift as the polymorphism for defence and competitiveness is lost (Scenario (d) in Figure 1).

These examples show that an abiotic stressor can alter the link from evolution to ecology through slowing down evolution. While the role of small and declining population sizes has been studied in other fields, it is rarely considered in studies of eco-evolutionary dynamics outside the context of evolutionary rescue [see contribution to the special issue by (Govaert et al., 2019)]. Studies of the same species in different environments might show how stress-induced changes in standing genetic variation influence the likelihood and timing of evolutionary rescue. For example, the speed of evolutionary rescue in experimental populations of the red flour beetle (Tribolium castaneum) increased with the mismatch between the mean phenotype of the population and its environment (Stewart et al., 2017). This study also showed that small population sizes resulted in lower standing genetic variation, due to inbreeding and/ or genetic drift. Similar effects of population size have been shown in mathematical models (Gomulkiewicz \& Houle, 2009; Uecker \& Hermisson, 2016; Yamamichi \& Ellner, 2016) and experiments (Bell \& Gonzalez, 2009; Cameron, Plaistow, Mugabo, Piertney, \& Benton, 2014; Gonzalez \& Bell, 2012; Low-Décarie et al., 2015).

In contrast to single-species studies, only a few studies have compared the eco-evolutionary dynamics of species interactions in different environments. Such studies allow testing for the important interaction between population size and standing genetic variation and its role in shaping the evolution-to-ecology link. In an experimental evolution study using a bacterial prey population, Hiltunen and co-authors (Hiltunen, Ayan, \& Becks, 2015) showed that evolution of an antipredatory defence was significantly delayed in the presence of reduced resources or of an abiotic stressor (salt) affecting only the predator, resulting in different predator-prey dynamics. How standing genetic variation was altered, was however not tested. Other examples include studies focusing on host-parasite interactions in different resource environments (Gómez et al., 2015; Harrison, 1994; Lopez Pascua et al., 2014; Lopez-Pascua \& Buckling, 2008) or in the presence of antimicrobial substances (Coulter, McLean, Rohde, \& Aron, 2014; Escobar-Páramo, Gougat-Barbera, \& Hochberg, 2012; Knezevic, Curcin, Aleksic, Petrusic, \& Vlaski, 
2013). While these studies show effects of environmental stress on the pace of host-parasite co-evolution, they do not examine the link from evolution to ecology (but see Cairns, Frickel, Jalasvuori, Hiltunen, \& Becks, 2017). Future studies on the role of abiotic stressors in eco-evolutionary dynamics should thus follow and contrast the genetic variation of interacting populations in the presence and absence of stressors, as well as complement data on population sizes with data on trait and fitness changes.

\subsection{Increase in genetic variation}

Genetic variation within both randomly mating and asexual populations is generally increased by mutation and dispersal, and these processes can thus drive adaptive evolution by introducing novel and adaptive alleles. Alternatively, if the introduced alleles or genotypes are maladaptive, this would limit adaptive evolution and eventually lead to breaking the evolution-to-ecology link.

The general relationship between DNA mutation rates and rates of adaptive evolution is still unclear (Lynch, 2010), as the mutations fuel sequences with the variability that is essential for adaptive evolution, while at the same time most mutations have a negative impact/are deleterious (Rainey, 1999; Sniegowski, Gerrish, \& Lenski, 1997). The presence of an abiotic stressor can have a direct impact on mutation rates, beyond its effect on population sizes discussed above. Mutation rates could be elevated under stressful conditions, leading potentially to the loss of function and eventually to the extinction of populations (Bull, Sanjuán, \& Wilke, 2007; Chen \& Shakhnovich, 2009; Martin \& Gandon, 2010). Under these circumstances, a prey population might become extinct or exhibit quarter-lag phase cycles without any evolution of antipredator defence (Figure 1). Other studies, however, showed that the presence of an abiotic stressor favours bacteria with an elevated mutation rate, because they generate adaptive mutations more rapidly and can exploit the resources of their environment more efficiently (Giraud et al., 2001; Oliver \& Mena, 2010). The rapid evolution of antipredatory defences could lead under these conditions to fast evolutionary rescue or a switch to antiphase cycles in both predator and prey when defence evolution

\section{Fitness in patch 1}

\section{Fitness in patch 2}
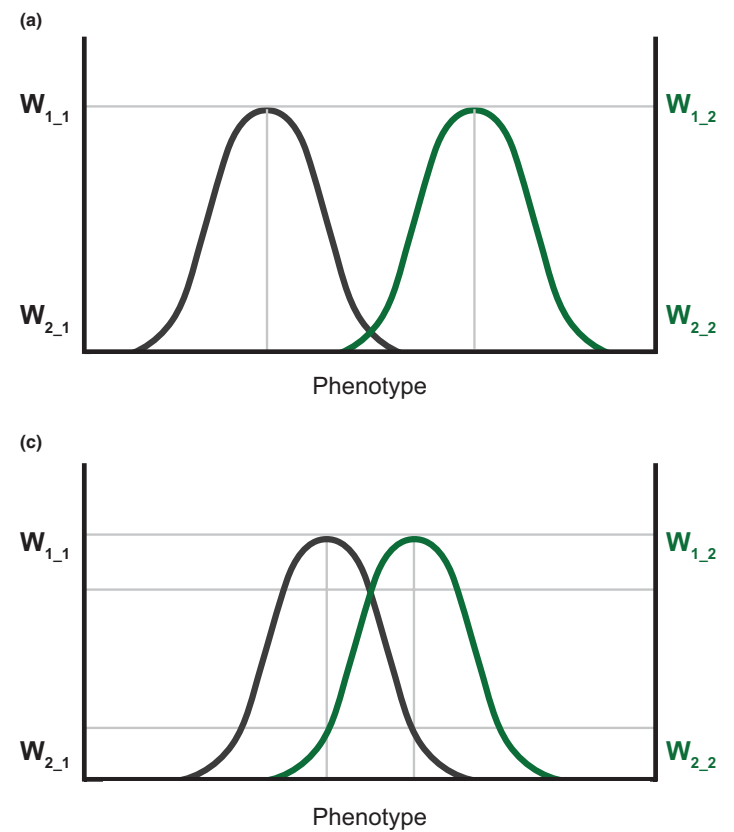

Phenotype
Population dynamics in Patch 2

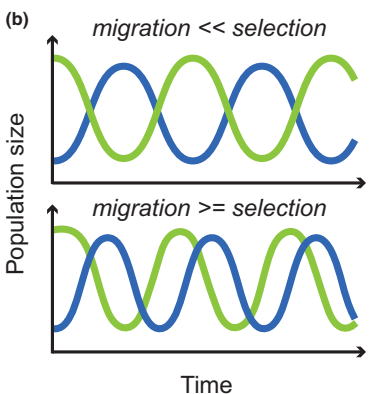

(d) migration $<$ selection

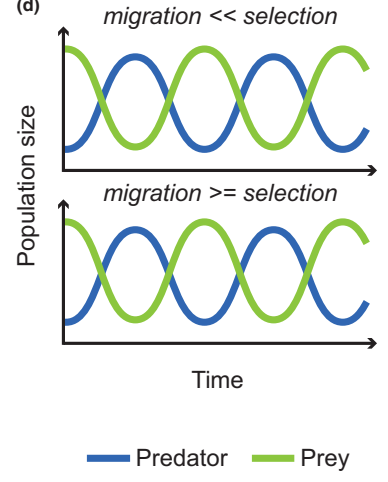

FIGURE 2 Fitness of locally adapted populations (a, c) and the predator-prey dynamics with gene flow (b, d). Fitness is denoted by $W_{i, j}$ where $i=$ origin of population (patch 1 or 2 ) and $j$ = current environment (patch 1 or 2). (a) Hypothetical scenario where phenotypes (antipredator defence with a cost of reduced competitiveness, abiotic stress resistance) are under stabilizing selection for different optima in patch 1 (= adapted to abiotic stress; black curve) and in patch 2 (= adapted to predation; green curve). Patch 1 has no predators, and patch 2 no abiotic stressor. (b) Antipredator defence is costly, and patch 2 harbours a polymorphism of defended and undefended prey, leading to antiphase cycles. With low migration rates and thus gene flow from patch 1 to patch 2 (i.e., migration « selection), little or no effect on the population dynamics is expected, and thus, the link between evolution and ecology is not altered. When migration is strong compared to selection (migration $\geq$ selection), the polymorphism in the two patches is lost (gene swamping by the undefended type), and the population dynamics will no longer be driven by defence evolution (antiphase cycles vanish). (c) Fitness is maximized in the local patch ( $W_{11}$ and $W$ $\left.2_{2} 2>0\right)$ and fitness in the foreign patch is low $\left(W_{1 \_2}\right.$ and $\left.W_{2 \_1} \ll 1\right)$. (d) We expect little or no effect on the eco-evolutionary dynamics. Vertical grey lines in a and c represent the fitness optima, and horizontal lines mark the fitness in the respective environments 
is costly. The role of mutation rates and mutation supply in ecoevolutionary dynamics is still unclear, but it should be of high relevance for mutation-limited systems, populations that reproduce mainly asexually and systems with low standing genetic variation.

Gene flow occurs when gametes or individuals migrate or disperse from one population to another. Spatial structure and migration/dispersal have been shown to play a large role for ecoevolutionary dynamics, for example, in meta-communities (Hanski \& Saccheri, 2006; Jousimo et al., 2014), or in the contexts of local adaptation (Reznick, Butler, \& Rodd, 2001) and invasion (Fronhofer $\&$ Altermatt, 2015). The effect of gene flow for eco-evolutionary dynamics depends on the phenotypic and fitness differences between the habitats as well as on how large selection is compared to migration (Figure 2). In the case where the fitness of locally adapted individuals is very low in the other patch (Figure 2a), with migration between the two patches, maladapted genotypes will be introduced from one patch into the other. When migration is sufficiently small compared to selection, there will be little or no effect on eco-evolutionary dynamics in patch 2 . With high gene flow, a large fraction of the prey population is maladapted, moving the population in a direction opposite to selection in the patch. Thus, local adaptation

will be lost quickly, and the evolution-to-ecology link will be broken (Figure 2b).

It is also possible that the fitness of locally adapted populations is greater than zero in the other environment but still smaller than in their own environment (Figure 2c). Independently of whether migration is small or large compared to selection, we expect little or no change in the predator-prey dynamics, since the level of defence will on average still be high and the eco-evolutionary feedback dynamics are thus maintained (Figure 2d). This will change when we make different assumptions about local adaptation with respect to the traits involved and their trade-offs. When local adaptation to the stressor confers at the same time some level of defence against the predator (e.g., through positive pleiotropic effects of a mutation, see below), successful invasion of individuals from patch 1 would be possible. Depending on the trait-fitness relationship in the specific system, the invader will out-compete the defended prey, the undefended prey or both, which will lead to a change in the population dynamics (see figure 4 in Ehrlich et al., 2017).

These scenarios show that local adaptation and gene flow can have consequences for eco-evolutionary dynamics when populations are locally adapted to an abiotic stressor or interact with other

\section{Abiotic stress for the prey}

(b)
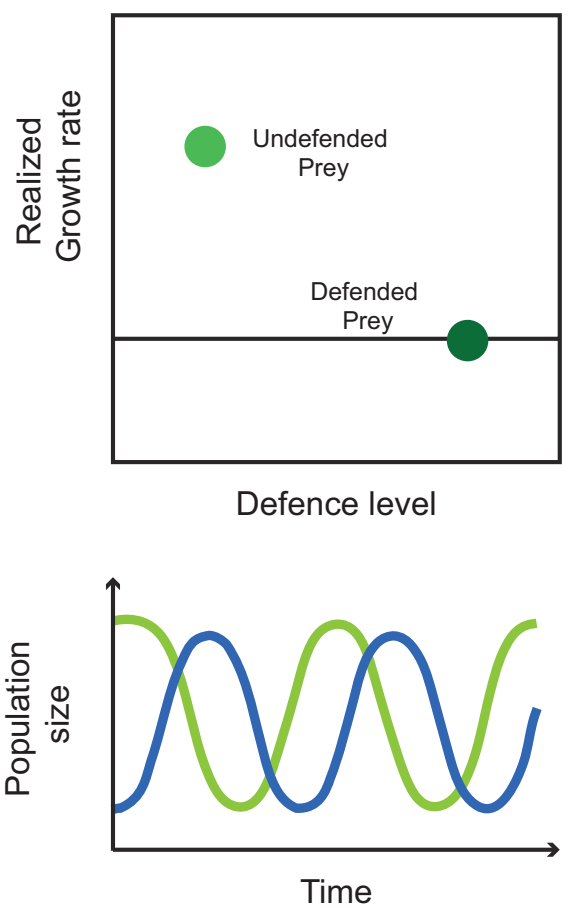

(c)
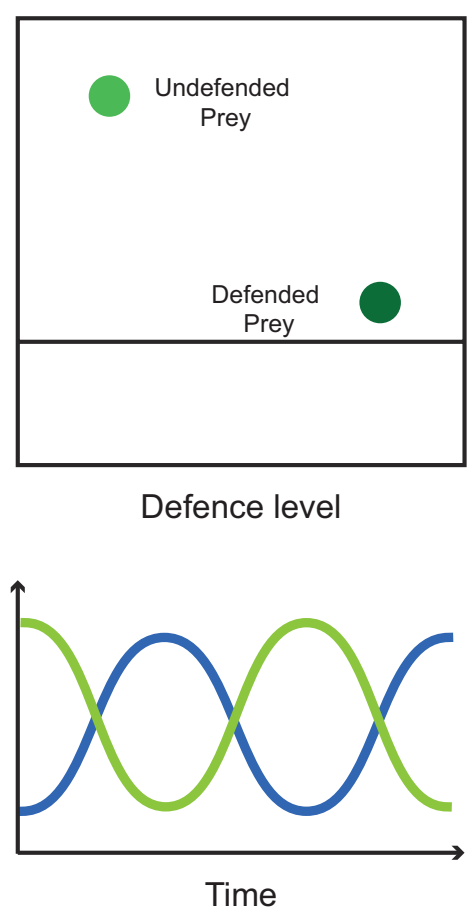
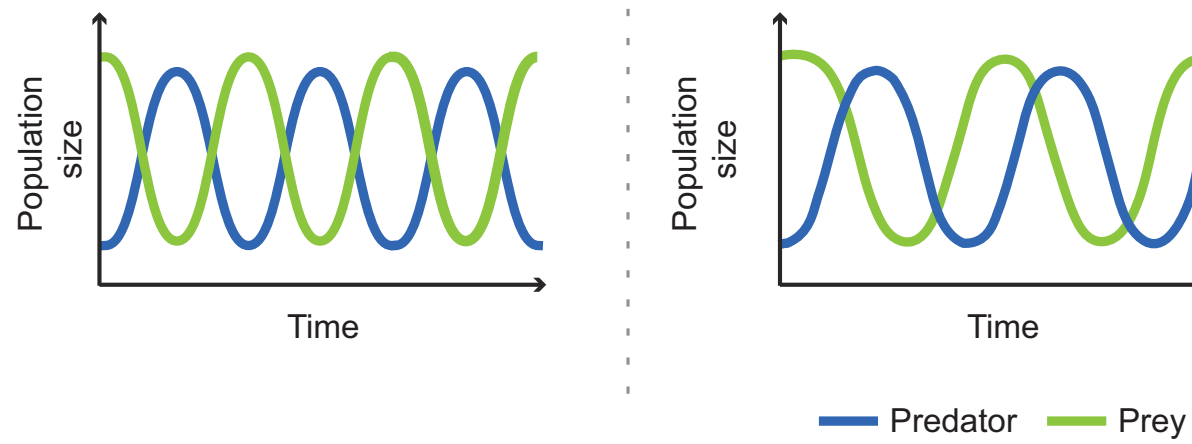

FIGURE 3 The effect of an abiotic stressor on the eco-evolutionary dynamics in the presence of a defence-growth trade-off for the prey in a predator-prey system (Figure 1, scenario (c)). (a) With a strong trade-off within the prey population, defended and undefended prey types can coexist with the predator and show characteristic antiphase cycling. (b) The same genotypes are assumed to be present in the prey population but with an additional abiotic stressor, which lowers the growth rates of these prey types in such a way that the realized net growth rate of the defended prey is zero or below, and hence, only undefended prey and the predator will be present, and we find classical predator-prey cycles. (c) When the realized growth rates are affected in such a way that the undefended type has a growth rate very close to zero, we expect to find eco-evolutionary dynamics, but the increase in the defended prey will slow down and cycles will be longer 
species. Based on previous work on local adaptation and gene flow (Brockhurst, Buckling, Poullain, \& Hochberg, 2007; Lenormand, Roze, \& Rousset, 2009; Lion \& Gandon, 2015; Morgan, Gandon, \& Buckling, 2005), prediction for eco-evolutionary feedback dynamics will depend on the exact mechanism of local adaptation (pleiotropic effects and trade-offs), and on the timing of invasion (Yamamichi, Yoshida, \& Sasaki, 2014), the predictions for the eco-evolutionary dynamics will change.

\subsubsection{Trade-Off}

Trade-offs between different traits are important for the maintenance of trait polymorphism within populations and are a key driver for eco-evolutionary dynamics. They can be the result of genetic, energetic, or engineering constraints (for the former, see the discussion below). Important examples are trade-offs between anti-consumer traits, for example, defence against a predator or resistance against a pathogen and traits involved in reproduction or competitiveness. The role of trade-offs for eco-evolutionary dynamics varies, however, with the trait range or variance (Becks et al., 2010; E. I. Jones et al., 2009) and the costs of the defence (Ehrlich et al., 2017; Huang et al., 2017; Yoshida et al., 2007). It can also change in the presence of an abiotic stressor (Figure 3). Consider the example in Figure 3, where defended prey has lower growth rate than undefended prey due to costs. In the simplest case, a stressor causes a decrease in growth rate of the same magnitude for both types of prey. If the stress is sufficiently strong, the growth rate of the defended prey might become negative leading to extinction of this phenotype (Figure 3b). As a consequence, the link between evolution and ecology will be altered and the populations will return to classical predator-prey cycles with the undefended prey only (i.e., the polymorphism in the prey is not maintained, and there is no eco-evolutionary feedback). When the reduction in fitness is less strong and the polymorphism in the prey population is maintained, the slower growth rates of the defended prey can lead to slower cycles, since the level of defence is the same as without the stressor, but the defence becomes costlier (Figure 3c).

Testing the prediction experimentally that a stressor can alter the role of the trade-off and thus whether we observe eco-evolutionary dynamics requires a priori information on the trade-off and its strength. Considering the increasing evidence for the role of trade-offs in eco-evolutionary dynamics, experimental approaches that allow the manipulation of the strength of the trade-off in prey populations through manipulation of the diversity within a population (Kasada et al., 2014; Meyer, Ellner, Hairston, Jones, \& Yoshida, 2006), it is possible to test how the strength of the trade-off in combination with different levels of an abiotic stressor can determine the potential for, the details of, the eco-evolutionary dynamics. These approaches should also be extended to larger communities.

\subsubsection{Other mechanisms}

In addition to the factors discussed above, the genetic architecture of selected and correlated traits can influence the rate of adaptation and thus have a potential to affect the evolution-to-ecology link. In particular, pleiotropy between different traits (Agrawal \& Stinchcombe, 2009) and epistatic interactions among mutations (Chou, Chiu, Delaney, Segrè, \& Marx, 2011; Cooper \& Lenski, 2000; Khan, Dinh, Schneider, Lenski, \& Cooper, 2011; MacLean, Hall, Perron, \& Buckling, 2010) can slow down or accelerate adaptive evolution. In the case of epistasis, the fitness effect of a mutation or an allele depends on the genetic environment in which it finds itself (Breen, Kemena, Vlasov, Notredame, \& Kondrashov, 2012; Elena \& Lenski, 1997; Kouyos, Silander, \& Bonhoeffer, 2007; Sackman \& Rokyta, 2018). Pleiotropy between two traits is positive when alleles that lead one trait closer to the optimum do the same for the second trait and negative in the opposite case. Antagonistic pleiotropy (e.g., between higher yield and reduced herbivore resistance (Rosenthal \& Dirzo, 1997), or between defence and competitiveness) limits evolutionary changes because it reduces the adaptive response of an organism (Orr, 2000; Welch \& Waxman, 2008). It can thus disfavour the evolution-to-ecology link in the presence of an abiotic stressor when the stressor for example intensifies metabolic costs of the defence, leading to lower predator and prey densities or a shift from cycling to steady-state dynamics.

Special cases of eco-evolutionary dynamics are cryptic cycling, where the total population size of the prey is constant but the proportions of the two prey types (defended and undefended) as well as the predator density cycle over time (Yoshida et al., 2007), and ecological pleiotropy where a trait change has more than one functional effect on an ecological process and suppresses or enhances ecological changes (DeLong, 2017; DeLong, Hanley, \& Vasseur, 2014). Ecological pleiotropy and cryptic dynamics are of special interest, as one could conclude that there is no interaction between evolution and ecology. The presence of an abiotic stressor could change this, when the stressor influences the functional effects of a trait in a way that do not suppress eco-evolutionary feedback. Another potential effect of adaptation to the stressor is an increase in the preys' growth rate, which can affect the ecological dynamics, for example, leading to a shift from steady state to cyclic dynamics.

\section{CONCLUSION}

In this paper, we have presented simplified scenarios where we hypothesize that the presence of an abiotic stressor alters the link between ecological and evolutionary dynamics in a predator-prey system. For almost all the discussed scenarios, we identified conditions where predictions for the eco-evolutionary dynamics based on a stressor-free environment were not valid in the presence of the stressor (Table 1). This includes cases where the evolution-to-ecology link is broken, that is, no evolutionary rescue occurs, where evolutionary change is significantly slowed down or where the stressor has only a small effect on the eco-evolutionary dynamics. Thus, phenotypes driving eco-evolutionary dynamics and the genomic basis of phenotypes with a large impact on population dynamics can be 


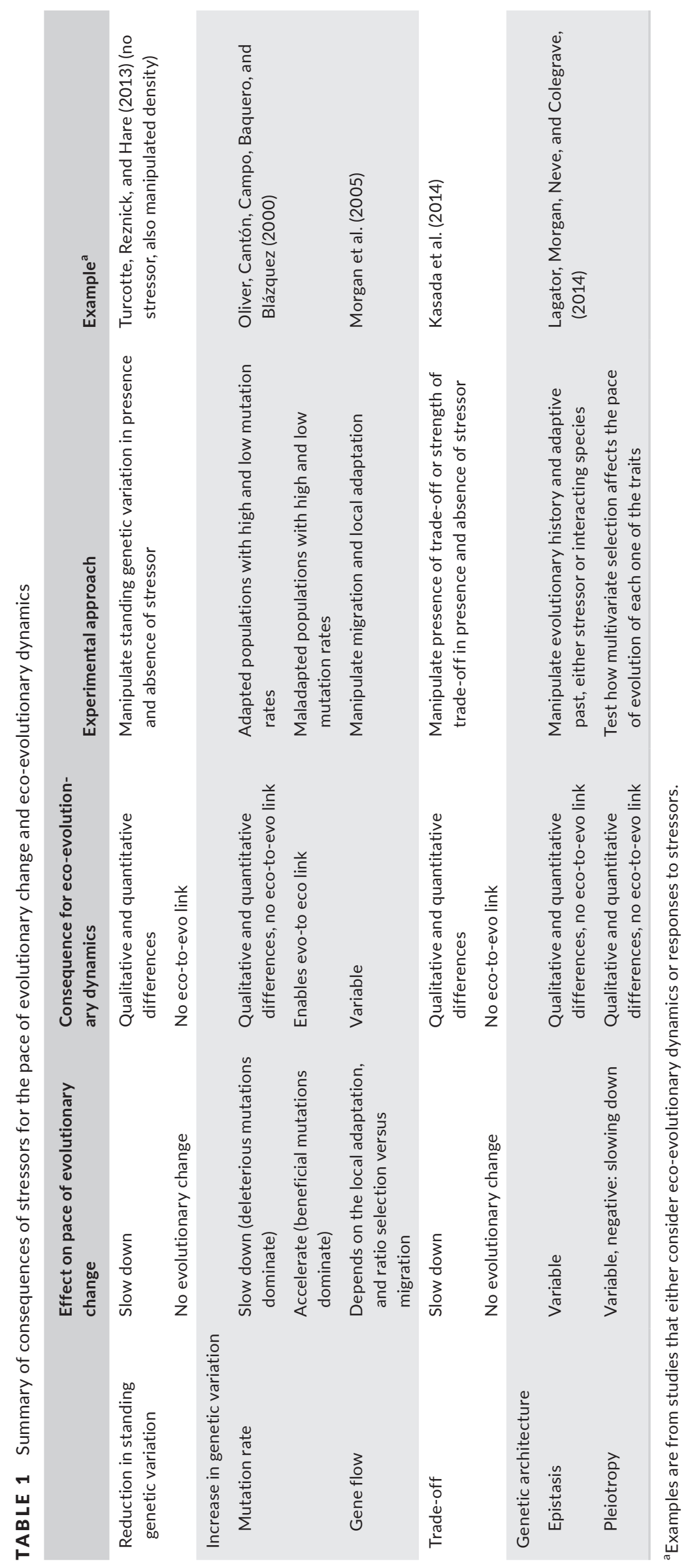


expected to be highly dependent on the environment. This insight is not novel, but it has consequences for the interpretation of the lack of evidence for eco-evolutionary dynamics and the relative contributions of ecological and evolutionary change to population dynamics, as well as for experimental design. The scenarios discussed here do not form a comprehensive list of potential mechanisms, and we have discussed only the simple case of a predator-prey system. They are, however, general enough to warrant a careful evaluation of eco-evolutionary dynamics in systems with more than one selective agent present at a time.

\section{ACKNOWLEDGEMENTS}

We are grateful to the guest editors for inviting us to contribute to this special issue. L.T. was supported by a stipend of the International Max-Planck Research School for Evolutionary Biology, L.B. by the German Research Foundation (BE 4135/9), and T.H. was supported by the Finnish Academy (Grant number 294666) and by the Helsinki Institute of Life Science (HiLIFE).

\section{AUTHOR CONTRIBUTIONS}

L.T., T.H. and L.B. conceived the ideas; L.T. and L.B. led the writing of the manuscript.

\section{ORCID}

Loukas Theodosiou (iD) https://orcid.org/0000-0001-6418-4652

Teppo Hiltunen (iD https://orcid.org/0000-0001-7206-2399

Lutz Becks (iD https://orcid.org/0000-0002-3885-5253

\section{REFERENCES}

Abrams, P. A., \& Matsuda, H. (1997). Prey Adaptation as a cause of predator-prey cycles. Evolution, 51(6), 1742-1750. https://doi. org/10.1111/j.1558-5646.1997.tb05098.x

Agrawal, A. F., \& Stinchcombe, J. R. (2009). How much do genetic covariances alter the rate of adaptation? Proceedings of the Royal Society $B$ : Biological Sciences, 276(1659), 1183-1191. https://doi.org/10.1098/ rspb.2008.1671

Alberti, M. (2015). Eco-evolutionary dynamics in an urbanizing planet. Trends in Ecology \& Evolution, 30(2), 114-126. https://doi. org/10.1016/j.tree.2014.11.007

Alberto, F. J., Aitken, S. N., Alía, R., González-Martínez, S. C., Hänninen, H., Kremer, A., ... Savolainen, O. (2013). Potential for evolutionary responses to climate change-evidence from tree populations. Global Change Biology, 19(6), 1645-1661. https://doi.org/10.1111/ gcb.12181

Andrade-Domínguez, A., Salazar, E., Del Carmen Vargas-Lagunas, M., Kolter, R., \& Encarnación, S. (2014). Eco-evolutionary feedbacks drive species interactions. ISME Journal, 8(5), 1041-1054. https://doi. org/10.1038/ismej.2013.208
Barbosa, P., \& Castellanos, I. (2005). Ecology of predator-prey interactions. Oxford, UK: Oxford University Press.

Barrett, R. D. H., \& Schluter, D. (2008). Adaptation from standing genetic variation. Trends in Ecology \& Evolution, 23(1), 38-44. https:// doi.org/10.1016/j.tree.2007.09.008

Bassar, R. D., Marshall, M. C., Lopez-Sepulcre, A., Zandona, E., Auer, S. K., Travis, J., ... Reznick, D. N. (2010). Local adaptation in Trinidadian guppies alters ecosystem processes. Proceedings of the National Academy of Sciences, 107(8), 3616-3621. https://doi.org/10.1073/ pnas.0908023107

Becks, L., Ellner, S. P., Jones, L. E., \& Hairston, N. G. Jr (2010). Reduction of adaptive genetic diversity radically alters eco-evolutionary community dynamics. Ecology Letters, 13(8), 989-997. https://doi. org/10.1111/j.1461-0248.2010.01490.x

Bell, G., \& Gonzalez, A. (2009). Evolutionary rescue can prevent extinction following environmental change. Ecology Letters, 12(9), 942-948. https://doi.org/10.1111/j.1461-0248.2009.01350.x

Breen, M. S., Kemena, C., Vlasov, P. K., Notredame, C., \& Kondrashov, F. A. (2012). Epistasis as the primary factor in molecular evolution. Nature, 490(7421), 535-538. https://doi.org/10.1038/nature11510

Brockhurst, M. A., Buckling, A., Poullain, V., \& Hochberg, M. E. (2007). The impact of migration from parasite-free patches on antagonistic host-parasite coevolution. Evolution, 61(5), 1238-1243. https://doi. org/10.1111/j.1558-5646.2007.00087.x

Brunner, F. S., Anaya-Rojas, J. M., Matthews, B., \& Eizaguirre, C. (2017). Experimental evidence that parasites drive eco-evolutionary feedbacks. Proceedings of the National Academy of Sciences, 114(14), 3678-3683. https://doi.org/10.1073/pnas.1619147114

Bull, J. J., Sanjuán, R., \& Wilke, C. O. (2007). Theory of Lethal Mutagenesis for Viruses. Journal of Virology, 81(6), 2930-2939. https://doi. org/10.1128/JVI.01624-06

Cairns, J., Frickel, J., Jalasvuori, M., Hiltunen, T., \& Becks, L. (2017). Genomic evolution of bacterial populations under coselection by antibiotics and phage. Molecular Ecology, 26(7), 1848-1859. https://doi. org/10.1111/mec.13950

Cameron, T. C., Plaistow, S. J., Mugabo, M., Piertney, S. B., \& Benton, T. G. (2014). Eco-evolutionary dynamics: experiments in a model system. In J. Moya-Laraño, J. Rowntree \& G. Woodward (Eds.), Advances in ecological research (pp. 171-2016). London, UK: Academic Press.

Charlesworth, B. (1971). Selection in density-regulated populations. Ecology, 52(3), 469-474. https://doi.org/10.2307/1937629

Chen, P., \& Shakhnovich, E. I. (2009). Lethal Mutagenesis in Viruses and Bacteria. Genetics, 183(2), 639-650. https://doi.org/10.1534/ genetics.109.106492

Chou, H. H., Chiu, H. C., Delaney, N. F., Segrè, D., \& Marx, C. J. (2011). Diminishing returns Epistasis among beneficial mutations decelerates adaptation. Science, 332(6034), 1190-1192. https://doi. org/10.1126/science.1203799

Cooper, V. S., \& Lenski, R. E. (2000). The population genetics of ecological specialization in evolving Escherichia coli populations. Nature, 407(6805), 736-739. https://doi.org/10.1038/35037572

Cortez, M. H. (2017). Genetic variation determines which feedbacks drive and alter predator-prey eco-evolutionary cycles. Ecological Monographs, 88(3), 353-371. https://doi.org/10.1002/ecm.1304

Coulter, L. B., McLean, R. J. C., Rohde, R. E., \& Aron, G. M. (2014). Effect of bacteriophage infection in combination with tobramycin on the emergence of resistance in Escherichia coli and Pseudomonas aeruginosa biofilms. Viruses, 6(10), 3778-3786. https://doi.org/10.3390/ v6103778

DeLong, J. P. (2017). Ecological pleiotropy suppresses the dynamic feedback generated by a rapidly changing trait. The American Naturalist, 189(5), 592-597. https://doi.org/10.1086/691100

DeLong, J. P., Forbes, V. E., Galic, N., Gibert, J. P., Laport, R. G., Phillips, J. S., \& Vavra, J. M. (2016). How fast is fast? Eco-evolutionary dynamics 
and rates of change in populations and phenotypes. Ecology and Evolution, 6(2), 573-581. https://doi.org/10.1002/ece3.1899.

DeLong, J. P., \& Gibert, J. P. (2016). Gillespie eco-evolutionary models (GEMs) reveal the role of heritable trait variation in eco-evolutionary dynamics. Ecology and Evolution, 6(4), 935-945. https://doi. org/10.1002/ece3.1959.

DeLong, J. P., Hanley, T. C., \& Vasseur, D. A. (2014). Predator-prey dynamics and the plasticity of predator body size. Functional Ecology, 28(2), 487-493. https://doi.org/10.1111/1365-2435.12199

Ehrlich, E., Becks, L., \& Gaedke, U. (2017). Trait-fitness relationships determine how trade-off shapes affect species coexistence. Ecology, 98(12), 3188-3198. https://doi.org/10.1002/ecy.2047

Elena, S., \& Lenski, R. (1997). Test of synergistic interactions among deleterious mutations in bacteria. Nature, 4762(1979), 395-398. https:// doi.org/10.1038/37108

Escobar-Páramo, P., Gougat-Barbera, C., \& Hochberg, M. E. (2012). Evolutionary dynamics of separate and combined exposure of Pseudomonas fluorescens SBW25 to antibiotics and bacteriophage. Evolutionary Applications, 5(6), 583-592. https://doi. org/10.1111/j.1752-4571.2012.00248.x

Frickel, J., Feulner, P. G. D., Karakoc, E., \& Becks, L. (2018). Population size changes and selection drive patterns of parallel evolution in a host-virus system. Nature Communications, 9(1), 1706. https://doi. org/10.1038/s41467-018-03990-7

Frickel, J., Sieber, M., \& Becks, L. (2016). Eco-evolutionary dynamics in a coevolving host-virus system. Ecology Letters, 19(4), 450-459. https://doi.org/10.1111/ele.12580

Fronhofer, E. A., \& Altermatt, F. (2015). Eco-evolutionary feedbacks during experimental range expansions. Nature Communications, 6(1), 6844. https://doi.org/10.1038/ncomms7844

Giraud, A., Matic, I., Tenaillon, O., Clara, A., Radman, M., Fons, M., \& Taddei, F. (2001). Costs and benefits of high mutation rates: Adaptive evolution of bacteria in the mouse gut. Science, 291(5513), 26062608. https://doi.org/10.1126/science.1056421

Gómez, P., Ashby, B., Buckling, A., Gomez, P., Ashby, B., \& Buckling, A. (2015). Population mixing promotes arms race host-parasite coevolution. Proceedings of the Royal Society B, 282(1798), 20142297. https:// doi.org/10.1098/rspb.2014.2297

Gomulkiewicz, R., \& Holt, R. D. (1995). When does evolution by natural selection prevent extinction? Evolution, 49(1), 201-207. https://doi. org/10.2307/2410305

Gomulkiewicz, R., \& Houle, D. (2009). Demographic and genetic constraints on evolution. The American Naturalist, 174(6), E218-E229. https://doi.org/10.1086/645086

Gonzalez, A., \& Bell, G. (2012). Evolutionary rescue and adaptation to abrupt environmental change depends upon the history of stress. Philosophical Transactions of the Royal Society B: Biological Sciences, 368(1610), 20120079. https://doi.org/10.1098/rstb.2012.0079

Govaert, L., Fronhofer, E. A., Lion, S., Eizaguirre, C., Bonte, D., Egas, M., ... Matthews, B. (2019). Eco-evolutionary feedbacks - theoretical models and perspectives. Functional Ecology, 33(1), 13-30. https:// doi.org/10.1111/1365-2435.13241

Grant, P. R., \& Grant, B. R. (2002). Unpredictable evolution in a 30-year study of Darwin's finches. Science, 296(5568), 707-711. https://doi. org/10.1126/science.1070315

Hairston, N. G. Jr, Ellner, S. P., Geber, M. A., Yoshida, T., \& Fox, J. A. (2005). Rapid evolution and the convergence of ecological and evolutionary time. Ecology Letters, 8(10), 1114-1127. https://doi. org/10.1111/j.1461-0248.2005.00812.x

Hanski, I., \& Saccheri, I. (2006). Molecular-Level Variation Affects Population Growth in a Butterfly Metapopulation. PLOS Biology, 4(5), e129. https://doi.org/10.1371/journal.pbio.0040129.

Harrison, S. (1994). Metapopulations and conservation. In P. J. Edwards, R. M. May \& N. R. Webb (Eds.), Large-scale ecology and conservation biology (pp. 111-128). Oxford, UK: Blackwell Scientific.
Hendry, A. P. (2017). Introduction and Conceptual Framework. In Ecoevolutionary dynamics (pp. 1-25). Princeton, N.J: Princeton University Press.

Hill, W. G. (1972). Probability of fixation of genes in populations of variable size. Theoretical Population Biology, 3(1), 27-40. https://doi. org/10.1016/0040-5809(72)90032-9

Hiltunen, T., Ayan, G. B., \& Becks, L. (2015). Environmental fluctuations restrict eco-evolutionary dynamics in predator-prey system. Proceedings of the Royal Society B, 282(1808), 20150013. https://doi. org/10.1098/rspb.2015.0013

Hiltunen, T., \& Becks, L. (2014). Consumer co-evolution as an important component of the eco-evolutionary feedback. Nature. Communications, 5(1), https://doi.org/10.1038/ncomms6226

Hiltunen, T., Kaitala, V., Laakso, J., \& Becks, L. (2017). Evolutionary contribution to coexistence of competitors in microbial food webs. Proceedings of the Royal Society B: Biological Sciences, 284(1864), 20170415. https://doi.org/10.1098/rspb.2017.0415

Hiltunen, T., Cairns, J., Frickel, J., Jalasvuori, M., Laakso, J., Kaitala, V., ... Becks, L. (2018). Dual-stressor selection alters eco-evolutionary dynamics in experimental communities. Nature Ecology \& Evolution, 2(12), 1974-1981. https://doi.org/10.1038/s41559-018-0701-5

Hörnfeldt, B. (1978). Synchronous population fluctuations in voles, small game, owls, and Tularemia in Northern Sweden. Oecologia, 32(2), 141-152. https://doi.org/10.1007/bf00366068.

Huang, W., Traulsen, A., Werner, B., Hiltunen, T., \& Becks, L. (2017). Dynamical trade-offs arise from antagonistic coevolution and decrease intraspecific diversity. Nature Communications, 8(1), 2059. https://doi.org/10.1038/s41467-017-01957-8.

Jones, A. G. (2008). A theoretical quantitative genetic study of negative ecological interactions and extinction times in changing environments. BMC Evolutionary Biology, 8(1), 119. https://doi. org/10.1186/1471-2148-8-119

Jones, E. I., Ferrière, R., \& Bronstein, J. L. (2009). Eco-evolutionary dynamics of mutualists and exploiters. The American Naturalist, 174(6), 780-794. https://doi.org/10.1086/647971.

Jones, L. E., \& Ellner, S. P. (2004). Evolutionary tradeoff and equilibrium in an aquatic predator-prey system. Bulletin of Mathematical Biology, 66(6), 1547-1573. https://doi.org/10.1016/j.bulm.2004.02.006

Jones, L. E., \& Ellner, S. P. (2007). Effects of rapid prey evolution on predator-prey cycles. Journal of Mathematical Biology, 55(4), 541-573. https://doi.org/10.1007/s00285-007-0094-6

Jousimo, J., Tack, A. J. M., Ovaskainen, O., Mononen, T., Susi, H., Tollenaere, C., \& Laine, A.-L. (2014). Ecological and evolutionary effects of fragmentation on infectious disease dynamics. Science, 344(6189), 1289-1293. https://doi.org/10.1126/science.1253621

Kasada, M., Yamamichi, M., \& Yoshida, T. (2014). Form of an evolutionary tradeoff affects eco-evolutionary dynamics in a predator-prey system. Proceedings of the National Academy of Sciences, 111(45), 1603516040. https://doi.org/10.1073/pnas.1406357111

Khan, A. I., Dinh, D. M., Schneider, D., Lenski, R. E., \& Cooper, T. F. (2011). Negative epistasis between beneficial mutations in an evolving bacterial population. Science, 332(6034), 1193-1196. https://doi. org/10.1126/science.1203801

Kimura, M. (1983). The neutral theory of molecular evolution. Cambridge, UK: Cambridge University Press.

Knezevic, P., Curcin, S., Aleksic, V., Petrusic, M., \& Vlaski, L. (2013). Phage-antibiotic synergism: A possible approach to combatting Pseudomonas aeruginosa. Research in Microbiology, 164(1), 55-60. https://doi.org/10.1016/j.resmic.2012.08.008.

Kouyos, R. D., Silander, O. K., \& Bonhoeffer, S. (2007). Epistasis between deleterious mutations and the evolution of recombination. Trends in Ecology \& Evolution, 22(6), 308-315. https://doi.org/10.1016/j. tree.2007.02.014

Krebs, C. J., Boutin, S., Boonstra, R., Sinclair, A. R. E., Smith, J. N. M., Dale, M. R. T., ... Turkington, R. (1995). Impact of Food and Predation on 
the Snowshoe Hare Cycle. Science, 269(5227), 1112-1115. https:// doi.org/10.1126/science.269.5227.1112

Lagator, M., Morgan, A., Neve, P., \& Colegrave, N. (2014). Role of sex and migration in adaptation to sink environments. Evolution, 68(8), 2296-2305. https://doi.org/10.1111/evo.12440

Lenormand, T., Roze, D., \& Rousset, F. (2009). Stochasticity in evolution. Trends in Ecology \& Evolution, 24(3), 157-165. https://doi. org/10.1016/j.tree.2008.09.014

Lion, S., \& Gandon, S. (2015). Evolution of spatially structured host-parasite interactions. Journal of Evolutionary Biology, 28(1), 10-28. https:// doi.org/10.1111/jeb.12551

Lopez Pascua, L., Hall, A. R., Best, A., Morgan, A. D., Boots, M., \& Buckling, A. (2014). Higher resources decrease fluctuating selection during host-parasite coevolution. Ecology Letters, 17(11), 1380-1388. https://doi.org/10.1111/ele.12337

Lopez-Pascua, L. D. C., \& Buckling, A. (2008). Increasing productivity accelerates host-parasite coevolution. Journal of Evolutionary Biology, 21(3), 853-860. https://doi.org/10.1111/j.1420-9101.2008. 01501.x

Low-Décarie, E., Kolber, M., Homme, P., Lofano, A., Dumbrell, A., Gonzalez, A., \& Bell, G. (2015). Community rescue in experimental metacommunities. Proceedings of the National Academy of Sciences, 112(46), 14307-14312. https://doi.org/10.1073/pnas.1513125112

Lynch, M. (2010). Evolution of the mutation rate. Trends in Genetics, 26(8), 345-352. https://doi.org/10.1016/j.tig.2010.05.003

MacLean, R. C., Hall, A. R., Perron, G. G., \& Buckling, A. (2010). The population genetics of antibiotic resistance: Integrating molecular mechanisms and treatment contexts. Nature Reviews Genetics, 11(6), 405-414. https://doi.org/10.1038/nrg2778

Macnair, M. (1997). The evolution of plants in metal-contaminated environments. In R. Bijlsma \& V. Loeschcke (Eds.), Environmental stress, adaptation, and evolution (pp. 3-24). Basel: Birkhäuser Verlag.

Martin, G., \& Gandon, S. (2010). Lethal mutagenesis and evolutionary epidemiology. Philosophical Transactions of the Royal Society B: Biological Sciences, 365(1548), 1953-1963. https://doi.org/10.1098/ rstb.2010.0058

Matthews, B., Aebischer, T., Sullam, K. E., Lundsgaard-Hansen, B., \& Seehausen, O. (2016). Experimental evidence of an eco-evolutionary feedback during adaptive Divergence. Current Biology, 26(4), 483489. https://doi.org/10.1016/j.cub.2015.11.070

Meyer, J. R., Ellner, S. P., Hairston, N. G. Jr, Jones, L. E., \& Yoshida, T. (2006). Prey evolution on the time scale of predator-prey dynamics revealed by allele-specific quantitative PCR. Proceedings of the National Academy of Sciences of the United States of America, 103(28), 10690-10695. https://doi.org/10.1073/pnas.0600434103

Morgan, A. D., Gandon, S., \& Buckling, A. (2005). The effect of migration on local adaptation in a coevolving host-parasite system. Nature, 437(7056), 253-256. https://doi.org/10.1038/nature03913

Oliver, A., Cantón, R., Campo, P., Baquero, F., \& Blázquez, J. (2000). High frequency of hypermutable Pseudomonas aeruginosa in cystic fibrosis lung infection. Science, 288(5469), 1251. https://doi.org/10.1126/ science.288.5469.1251

Oliver, A., \& Mena, A. (2010). Bacterial hypermutation in cystic fibrosis, not only for antibiotic resistance. Clinical Microbiology and Infection, 16(7), 798-808. https://doi.org/10.1111/j.1469-0691.2010.03250.x

Orr, H. A. (2000). The rate of adaptation in asexuals. Genetics, 155(2), 961-968. http://www.ncbi.nlm.nih.gov/pubmed/23979572

Pimentel, D. (1968). Population regulation and genetic feedback. Science, 159(1963), 1432-1437. https://doi.org/10.1126/ science.159.3822.1432

Post, D. M., \& Palkovacs, E. P. (2009). Eco-evolutionary feedbacks in community and ecosystem ecology: Interactions between the ecological theatre and the evolutionary play. Philosophical Transactions of the Royal Society B: Biological Sciences, 364(1523), 1629-1640. https://doi.org/10.1098/rstb.2009.0012
Rainey, P. B. (1999). Evolutionary genetics: The economics of mutation. Current Biology, 9(10), R371-R373. https://doi.org/10.1016/ S0960-9822(99)80230-9

Raynes, Y., \& Sniegowski, P. D. (2014). Experimental evolution and the dynamics of genomic mutation rate modifiers. Heredity, 113(5), 375380. https://doi.org/10.1038/hdy.2014.49

Reznick, D. (1982). The Impact of Predation on Life History Evolution in Trinidadian Guppies: Genetic Basis of Observed Life History Patterns. Evolution, 36(6), 1236-1236. https://doi.org/10.2307/2408156

Reznick, D., Butler, M. J. IV, \& Rodd, H. (2001). Life-history evolution in guppies. VII. The comparative ecology of high- and low-predation environments. The American Naturalist, 157(2), 126-140. https://doi. org/10.1086/318627

Rosenthal, J. P., \& Dirzo, R. (1997). Effects of life history, domestication and agronomic selection on plant defence against insects: Evidence from maizes and wild relatives. Evolutionary Ecology, 11(3), 337-355. https://doi.org/10.1023/A:1018420504439

Sackman, A. M., \& Rokyta, D. R. (2018). Additive phenotypes underlie Epistasis of fitness effects. Genetics, 208(1), 339-348. https://doi. org/10.1534/genetics.117.300451.

Sniegowski, P. D., Gerrish, P. J., \& Lenski, R. E. (1997). Evolution of high mutation rates in experimental populations of E. coli. Nature, 387(6634), 703-705. https://doi.org/10.1038/42701

Steinberg, D. S., Losos, J. B., Schoener, T. W., Spiller, D. A., Kolbe, J. J., \& Leal, M. (2014). Predation-associated modulation of movementbased signals by a Bahamian lizard. Proceedings of the National Academy of Sciences, 111(25), 9187-9192. https://doi.org/10.1073/ pnas.1407190111

Steiner, C. F., \& Masse, J. (2013). The stabilizing effects of genetic diversity on predator-prey dynamics. F1000Research, 2, 43. https://doi. org/10.3410/f1000research.2-43.v1

Stewart, G. S., Morris, M. R., Genis, A. B., Szúcs, M., Melbourne, B. A., Tavener, S. J., \& Hufbauer, R. A. (2017). The power of evolutionary rescue is constrained by genetic load. Evolutionary Applications, 10(7), 731-741. https://doi.org/10.1111/eva.12489

Travis, J., Reznick, D., Bassar, R. D., López-Sepulcre, A., Ferriere, R., \& Coulson, T. (2014). Do eco-evo feedbacks help us understand nature? Answers from studies of the Trinidadian guppy. Advances in Ecological Research, 50, 1-40. https://doi.org/10.1016/B978-0-12-801374-8.00001-3

Turchin, P. (2003a). Complex population dynamics: A theoretical/empirical synthesis. Princeton, NJ: Princeton University Press.

Turchin, P. (2003b). Evolution in population dynamics. Nature, 424(6946), 257-258. https://doi.org/10.1038/424257a

Turcotte, M. M., Reznick, D. N., \& Hare, J. D. (2013). Experimental test of an eco-evolutionary dynamic feedback loop between evolution and population density in the green peach aphid. American Naturalist, 181(S1), S46-S57.

Uecker, H., \& Hermisson, J. (2016). The role of recombination in evolutionary rescue. Genetics, 202(2), 721-732. https://doi.org/10.1534/ genetics.115.180299

Utida, S. (1957). Cyclic fluctuations of population density intrinsic to the host-parasite system. Ecology, 38(3), 442-449. https://doi. org $/ 10.2307 / 1929888$

van Velzen, E., \& Gaedke, U. (2017). Disentangling eco-evolutionary dynamics of predator-prey coevolution: The case of antiphase cycles. Scientific Reports, 7(1), 17125. https://doi.org/10.1038/s41598-017-17019-4

Walsh, M. R., \& Post, D. M. (2011). Interpopulation variation in a fish predator drives evolutionary divergence in prey in lakes. Proceedings of the Royal Society B: Biological Sciences, 278(1718), 2628-2637. https://doi.org/10.1098/rspb.2010.2634

Welch, J. J., \& Waxman, D. (2008). Calculating independent contrasts for the comparative study of substitution rates. Journal of Theoretical Biology, 251(4), 667-678. https://doi.org/10.1016/j.jtbi.2007.12.015

Wright, S. (1931). Evolution in mendelian populations. Genetics, 16(2), 97-159. 
Wright, S. (1968). Evolution and the Genetics of Populations: Genetic and biometric foundations. Chicago, IL: University of Chicago Press.

Yamamichi, M., \& Ellner, S. P. (2016). Antagonistic coevolution between quantitative and Mendelian traits. Proceedings of the Royal Society B, 283(1827), 20152926. https://doi.org/10.1098/rspb.2015.2926

Yamamichi, M., Yoshida, T., \& Sasaki, A. (2014). Timing and propagule size of invasion determine its success by a time-varying threshold of demographic regime shift. Ecology, 95(8), 2303-2315. https://doi. org/10.1890/13-1527.1

Yoshida, T., Ellner, S. P., Jones, L. E., Bohannan, B. J. M., Lenski, R. E., \& Hairston, N. G. Jr (2007). Cryptic population dynamics: Rapid evolution masks trophic interactions. PLoS Biology, 5(9), 1868-1879. https://doi.org/10.1371/journal.pbio.0050235

Yoshida, T., Jones, L. E., Ellner, S. P., Fussmann, G. F., \& Hairston, N. G. Jr (2003). Rapid evolution drives ecological dynamics in a predatorprey system. Nature, 424(6946), 303-306. https://doi.org/10.1038/ nature01767 